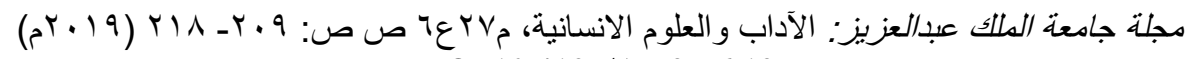

$$
\begin{aligned}
& \text { DOI:10.4197/Art.27-6.13 }
\end{aligned}
$$

\title{
المشكلة الكردية في ظل الجمهورية التركية
}

\author{
إعداد الطالبة : أحلام علي الزهراني \\ $\mid \wedge \ldots \leq 1 \wedge$ \\ كلية الآداب والعلوم الإنسانية - قسم التاريخ \\ المملكة العربية السعسودية - جامعة الملك عبد العزيز
}

مستخلص. العلاقة الكردية في ظل الجمهورية التركية، ابتداء من الحركة الكمالية 9 الو ام وما صاحبها من احداث مع الاصرار الكردي على اقامة دولة كردستان.

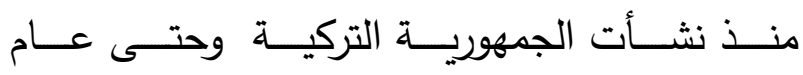

المقدمة

.5 r...

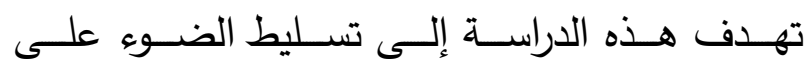

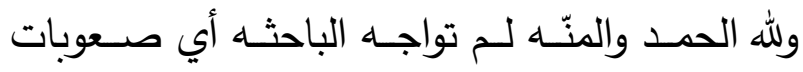

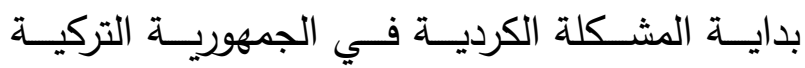

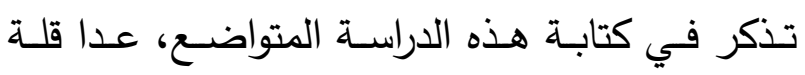

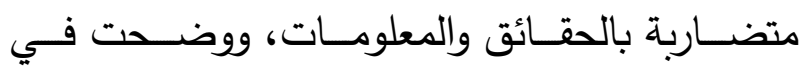

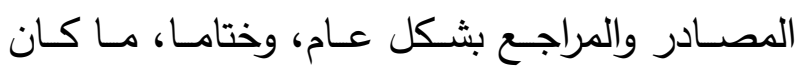

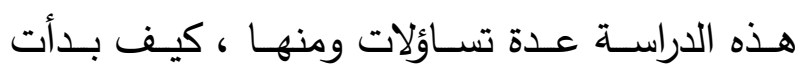
في البحـث مـن صــواب فمـن الله وحـده ومــا كـان وحسان

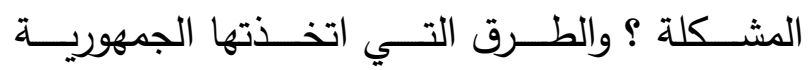
فيه من خطأ فمني ومن الثيطان، التركيـة في التعامـل مـع المشـكلة ؟ وعـدد الاكـراد

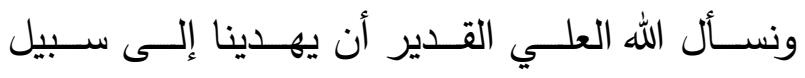

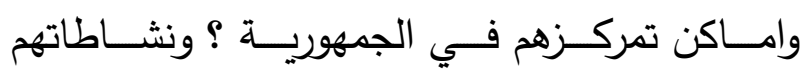
الرشاد والهدى، إنه وليّ ذلك والقادر عليه.

محاولاتهم في انشاء وطن قومي خاص بهج?

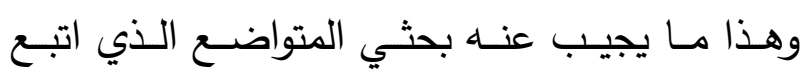

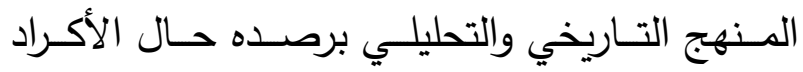


العثانيين الروحي والديني والمذهبي، (؟) وتمكن في مطلع القرن السادس عشر من دخول تبريز عاصمة

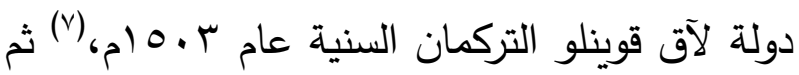
انصرف الى تحقيق أهدافه القومية العنصرية وذلك

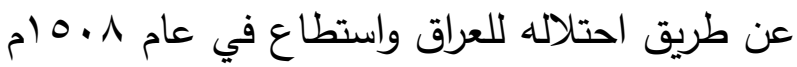

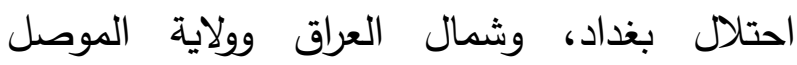
وسناجقها الكردية.(^) وفي تلك الفترة تعرض الاكراد الى ظلم وعدوان شديدين على يد الغزاة الصفويين. (9. الفصل الاول

\section{المشكلة الكردية في تركيا}

$$
\text { - المبحث الاول }
$$

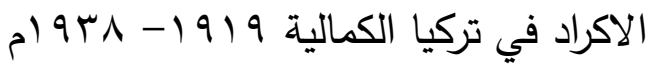
- - المبحث الثاني الاكراد والجمهورية التركية بعد

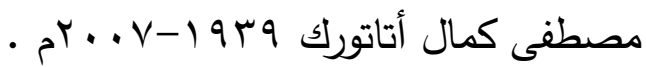

$$
\text { المبحث الاول }
$$

\section{الاكراد والحركة الكمالية 91919 - 19 19 الاول}

تعتبر الجمهوريـة التركيـة وريثة الجزء المتبقي مـن مقاطعـات الامبراطوريـة العثمانيـة ،الواسعة الارجـاء

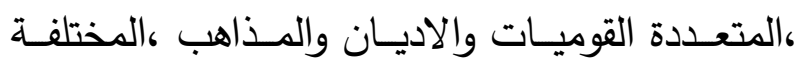

$$
\text { الثقافات والعادات والمستويات . (·) (1) }
$$

دار الموصلي، منذر، القضية الكردية في العر اق البعث و الأكر اد، (دمشق:

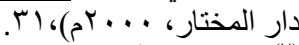

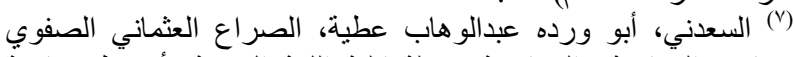

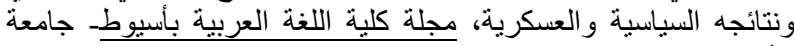

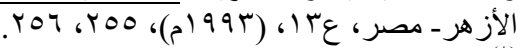

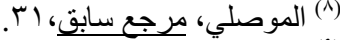
(9) البر الك، فاضل، مصطفى البارز اني الأسطورة و الحقيقة، (د.م، مطابع

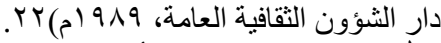

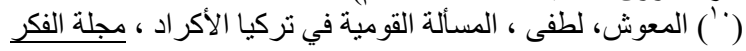

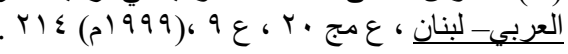

\section{التمهيد}

ظهر الاسلام في القرن السابع الميلادي ، ودخل الكرد جميعا في الدين الاسلامي ،إذا خلصهم من الديع الحكم الساساني الجائر دون التدخل في شؤونهم الداخلية ،فأبقى الفاتحون على تتظيماتهم الداخلية

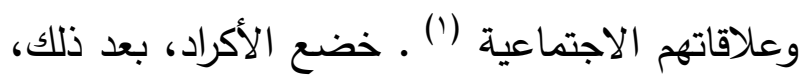

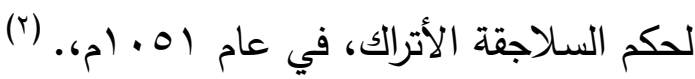

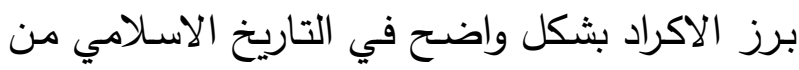

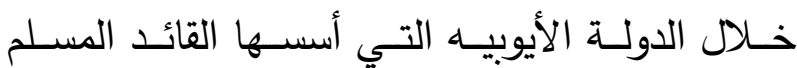

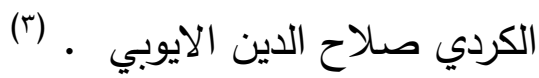
وفي القرن الثالث عشر الميلادي كان موعد الكُرد

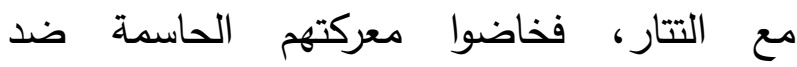

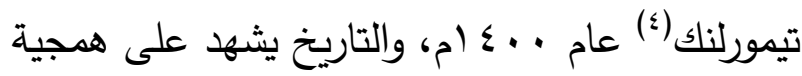
المغول التي اتصفت بالثدة والعنف، جوبهوا المغول

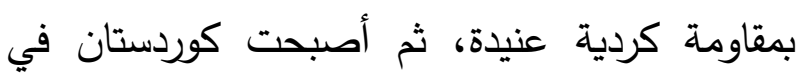
النهاية جزءاً من الامبراطورية المغولية. (0) وفي بداية القرن السادس عشر الميلادي أعلن الثاه

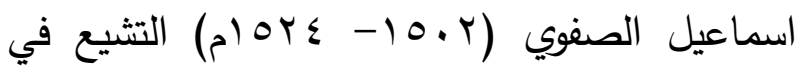
إيران، وكان يهدف من ذلك هو التحرر من نفوذ

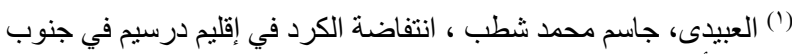

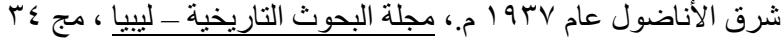

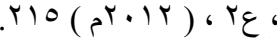

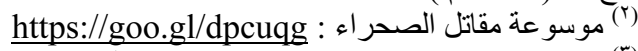

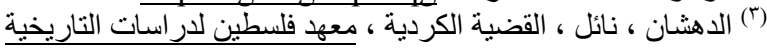

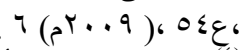

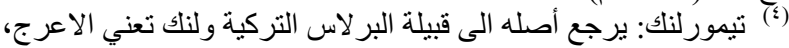

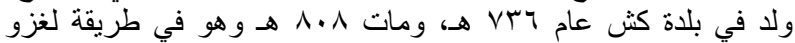

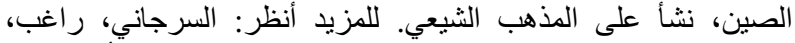

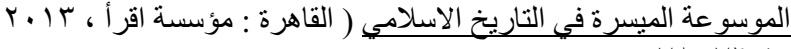
(0) هروتي، مرجع سابق، 1 1، 19. 
الاستقلالية التركية ،وتعرف باسم " الحركة الكمالية.

حرص مصطفى كمال أتاتورك على ضمان انضمام الأكـراد إليـه، في حركته الاسـتقلالية التركيـة. فأخذ يؤثر في زعماء الأكراد، ويطلب منهم إرجاء القضية الكرديـة ريثـا يكتمـل تحريـر البلاد التركيـة كلها مـن

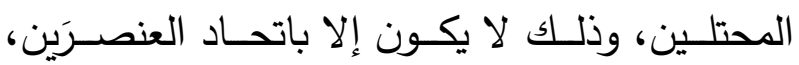

$$
\text { التركي والكردي . (lv) }
$$

دعـا مصـطفى كمـال القيـادات الكرديـة ،الـى مـؤتمر أرضروم في عام 919 (م .أيضا من نفس العام الى ملى مـؤتمر سـيواس، وعـدهم بـأن سـتكون للكـرد حقـوق

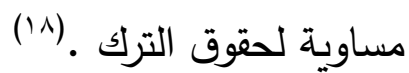
وتبـين قـرارات مـؤتمري أضــروم وسـيواس ، وبنـود الميثاق القومي • ب 9 ام الاساسية على السواء ،الذي عبرت أكثرية النواب فيه عن مصسالح الكمالين ،و ان الكماليين لم يعترفوا بحقوق الاكراد القوميـة ،وحاولوا

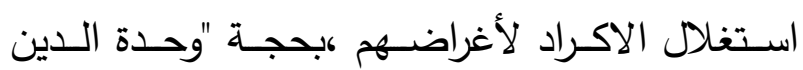

$$
\text { والامه " . (19) }
$$

وفي أعقاب إنهيـار الامبراطوريـة العثمانيـة ،نهضـــ شـعوب المنطقـة مطالبـة بالحريـة والاستقلال ،طالب الشـعب الكردي بحقوقـه شـأنه في ذلك شـأن شعوب

Sever المنطقة الاخرى ، وجاءت معاهدة سيفري

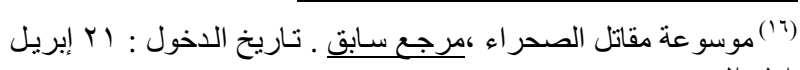

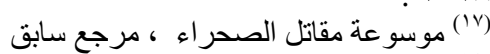

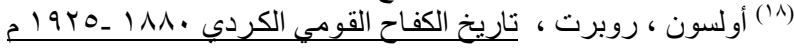

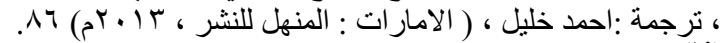

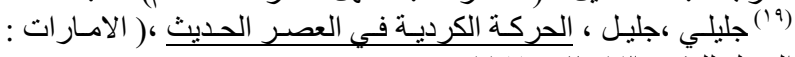

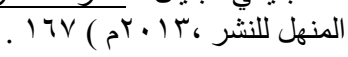

في عـام 7 ا9 ام وبموجـب اتفاقيـة سـايكس بيكـو Sykes Pico كردسـتان ضـمن تقسـيم الاراضـي العثمانيـة "الرجـل المـريض" لان كردسـتان دخلــ ضـــن نقـاط دول الحلفاء (r') ، وتوزعت على عدة دو منها : سوريا والاتحساد السـوفيتي والعـراق ، وهـذا التقسـيم يعتبـر الســبب الاساســي وراء محنــة كردسـتان والثــعب

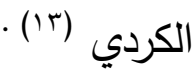

ارسلت السلطات العثمانية مصطفى كمال باشـا (ء) الـى المنطقـة الشـرقية ومنحتـه سـلطات وصـلاحيات واستعة كمفتش للجيش الثالث ،ومـع العمل على نزع السلاح هذا الجيش ،ولكن مصطفى كمال (10) ما ان وصل الحى مدينـة سامسون عن طريق البحر الاسود في 19 مسارس 919 (م حتى بـدأ يجمـع الانصسار والمؤيــدين ،ومــن الرافضــين لسياســـة الاستســلام والخضـوع للمحتلين ومنـذ ذلك اليـوم بـدأت الحركة

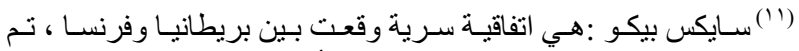

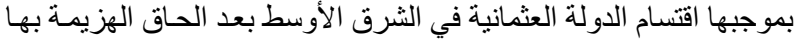

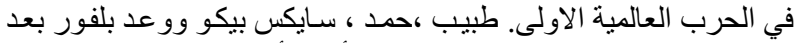

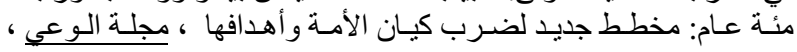
r.

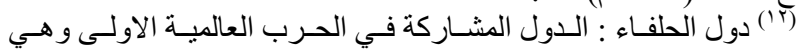

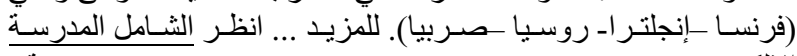
الإلكتروني.

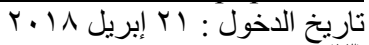

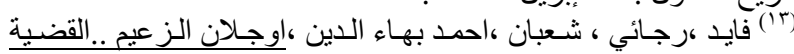

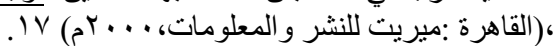

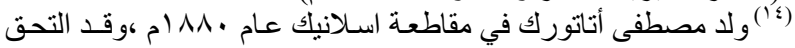

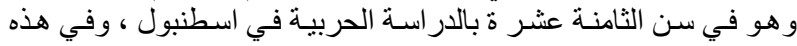

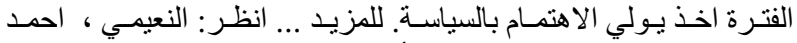

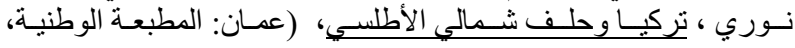

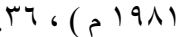

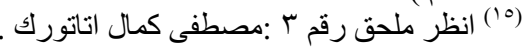


لقد استهلت جمهوريـة تركيا بقيادة مصطفى كمال " اتاتورك "مشوارها السياسي بتهميش حقوق الاقليات

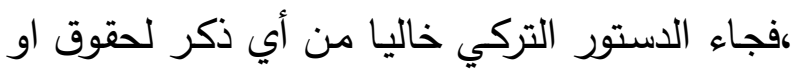

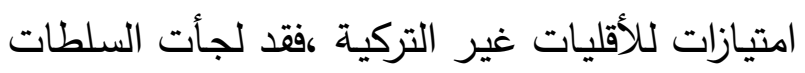
التركيـة السى صـهرهم وتـذويبيهم في الدولــة التركيـة الجديدة ـ وكـان أبرز مظـاهر هذه السياسـة ،إعدام

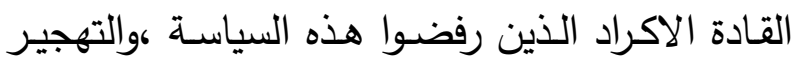

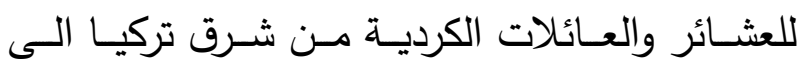
المناطق الغربية ،إصدار صدار القوانين التي تمنع

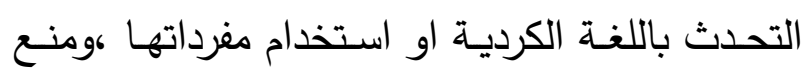

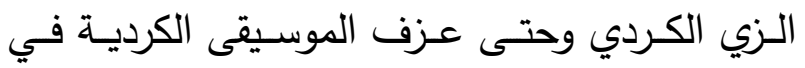
احتفالاتهم . (r) والواقع أن والمسألة الكرديـة في تركيا تمثل معضلة حيـة مـا إن تهدأ لفترة حتى تتفجر مـ من جديد. (ro)

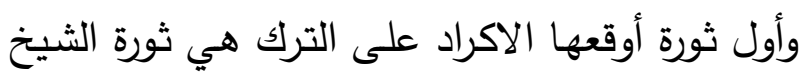

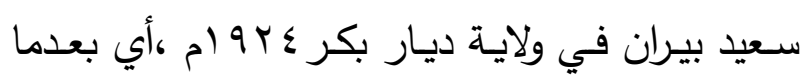

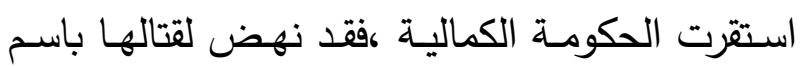

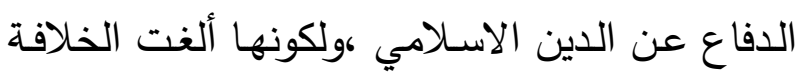

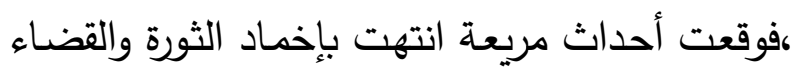

عليها (r)

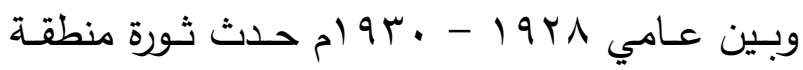
آغري "جبال أرارات " ،التي تشكل ثاني ثورة كرديـة

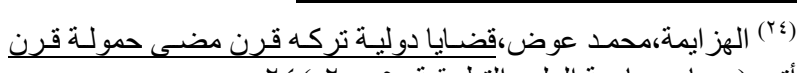

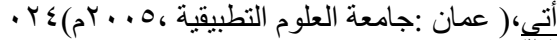

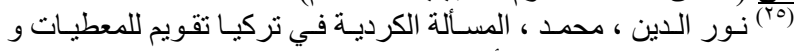

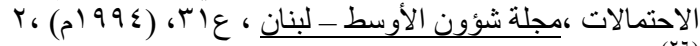

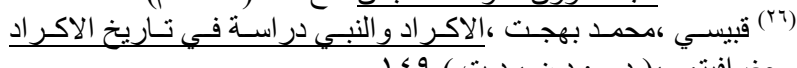

بين دول الحلفاء والعثمانيين في ابr 19 م ، تمهيدا

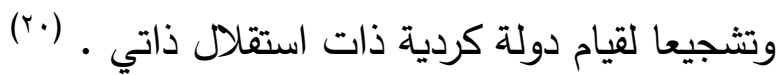

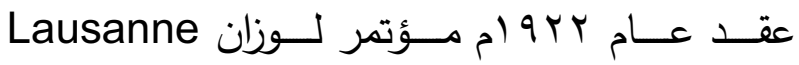
بسويسرا ، كان هدف المؤتمر التفاوض على معاهدة جديدة مـع تركيـا، التي رفضـت الاعتراف بمعاهدة سيفر • وكانت بريطانيا وفرنسا على استعداد للتنازل عن بعض امتيازاتهما مـع تركيا، خوفا من ان تلجئ ونئ

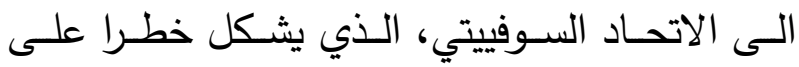

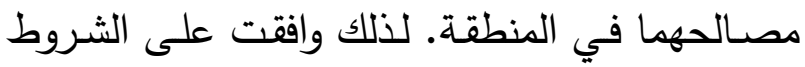
التركيـة ، وبـذلك تعـززت مواقـع تركيـا في المنطقـة وعلى الساحة الدولية، وتغيرت موازين القوى لصالح حكومة التركية التي انفردت بالحكم في تركيا، بإلغاء

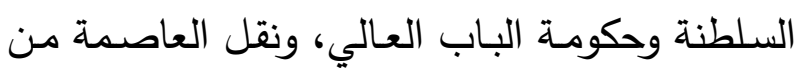
اسطنبول إلى أنقرة، وإلغـاء الخلافـة وإعـلان النظـام

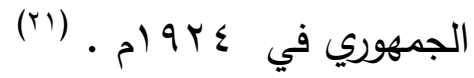

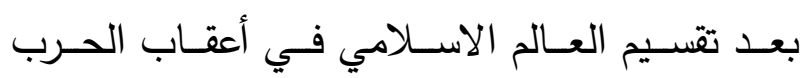

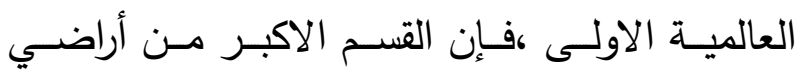

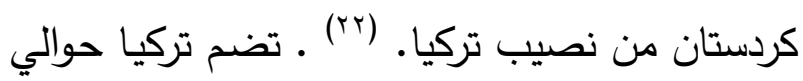

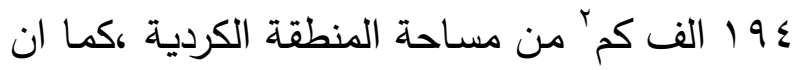

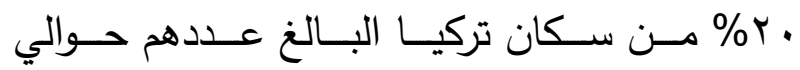

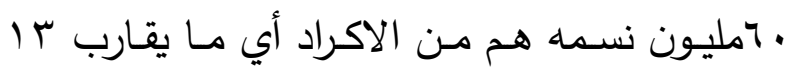

مليون نسمة . (r)

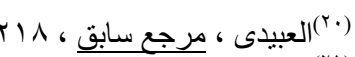

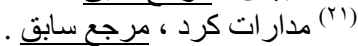

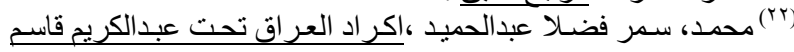

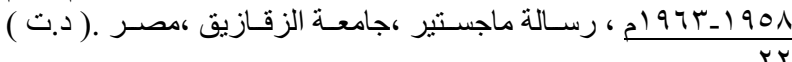

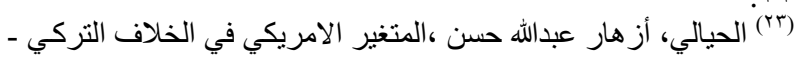

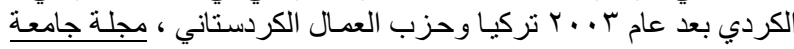

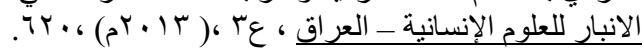


واقتصر سعيها إلى تطوير العلاقات مع الأكراد من

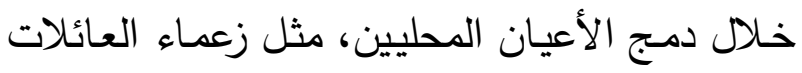

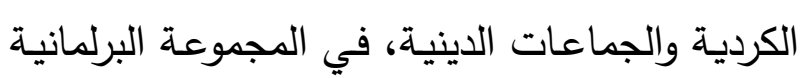
الخاصة بهم. (بr) شكل عهد الانقلابات العسكرية، الذي بدأ في العام

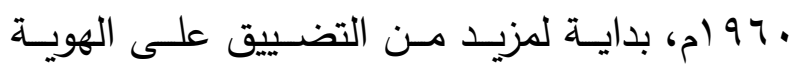

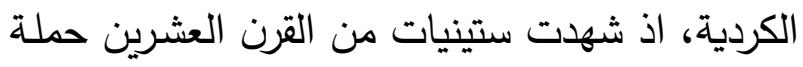

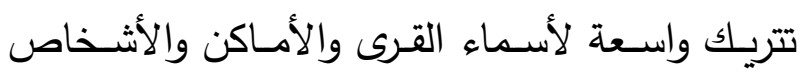

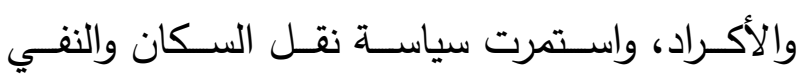

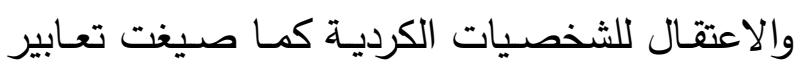
ملطفة “كالأتراك الجبليين"، ثم "المواطنين الشرقيين"، للإشارة إلى الأكراد. (r) شهـت تركيا موجة من الافكار والنشـاطات الثوريـة التي اخذت من الجامعات والمنتديات الفكريـة منابر

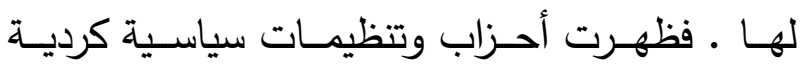

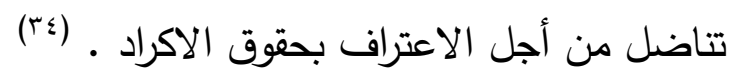

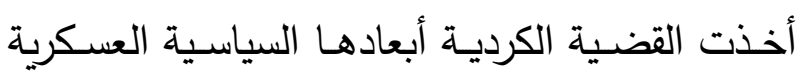

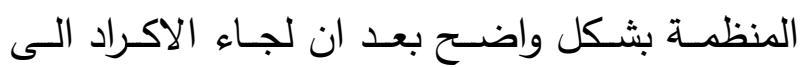

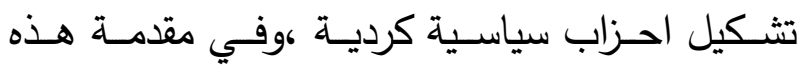
الاحزاب وأكثرها أهية هو حزب العمال الكردستاني المعروف " PKK " وهي الاحرف الاولى من اسمه هربه

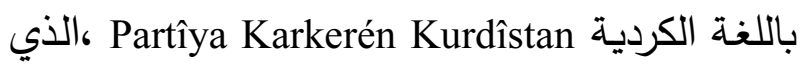

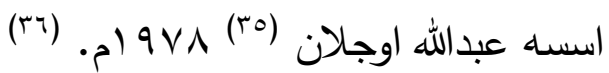

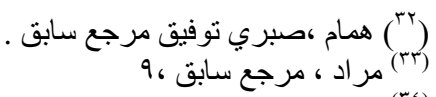

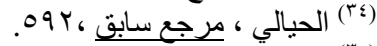

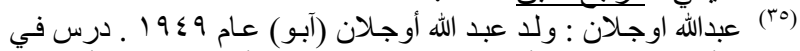

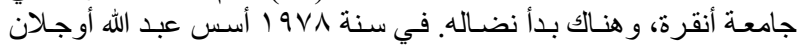

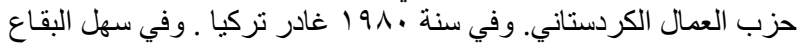

كبيرة في العهد الكمالي • (rV) وايضا ثورة درسيم عام

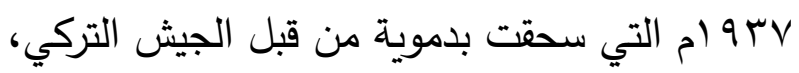
وخلفت الاف القتلى والجرحى . (r^) المبحث الثاني الاكراد والجمهورية التركية بعد

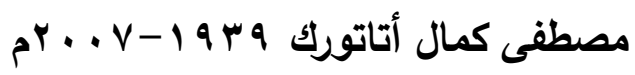

لم يكن وفـاة مصطفى كمـال" أتاتورك"، في العـام ^r 19 ام، الى إنهاء التدابير التعسفية تجاه الأكراد، بل استمرت بأوجه مختلفة ـ (ra)

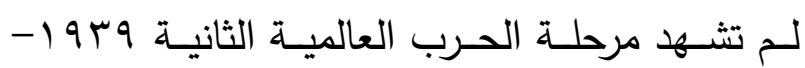

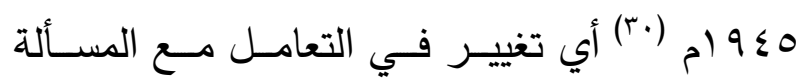
الكرديـة ، بل ظلت تركيا تعمل على تعزيز رؤيتها

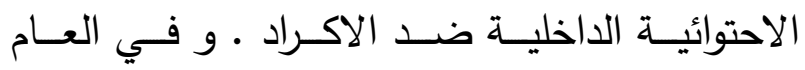

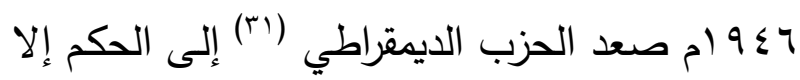

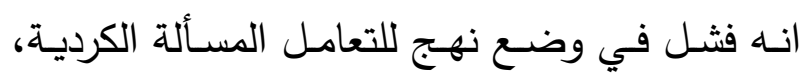

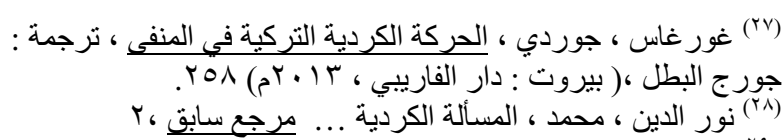

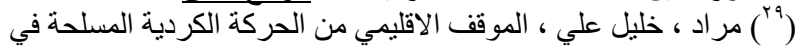

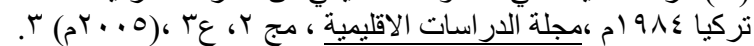

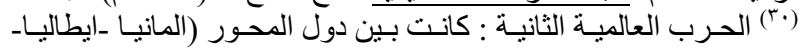

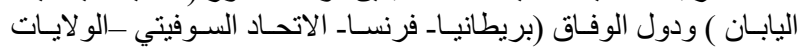

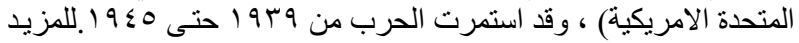

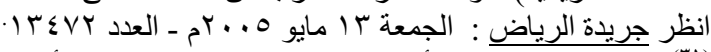

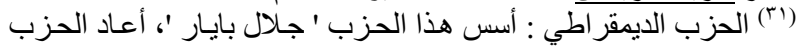

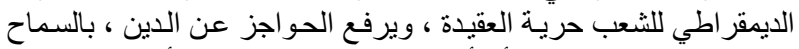

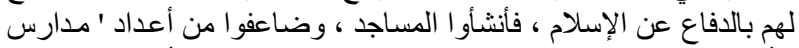

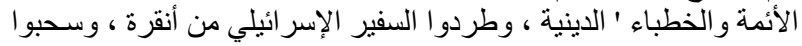

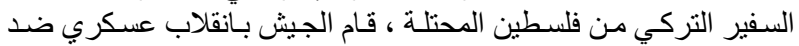

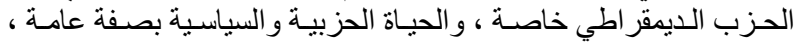

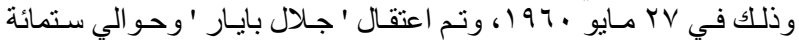

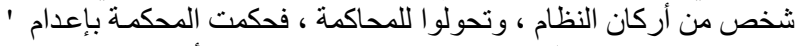

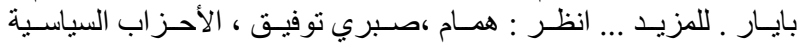

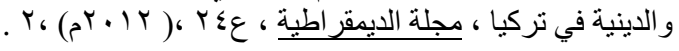


العراقي ـ اذ شهد عقد ثمانينيات القرن الماضي أكثر فترات الصـراع بين الأكراد والجيش التركي دمويـة . .

وفي تسعينيات ، تراجع حزب العمال الكردستاني عن

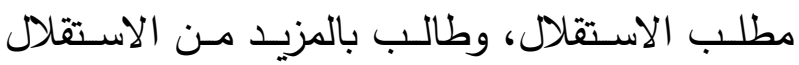

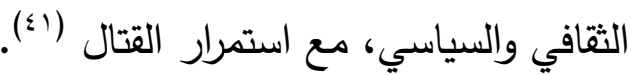
استمر الصراع مفتوحا بين النزعتين الكردية والتركية، على الصعيد السياسي والعسكري والدولي الى ان تم اعتقال زعيم حركة حزب العمال الكردستاني ،عبدالله اوجـلان ،حيث تم محاكمتهـه وصدر حكم الاعدام (\&r) م) 999 ونتيجـة للضـغوط السياسية والعسكرية التي أعقبـت الاعتقال والدحاكمة أعلن الحزب وقف إطلاق النار

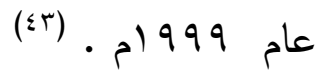
وقد واجهت الحكومـة التركيـة بسبب سياستها تجـاه الاكراد انتقادات واسعة في المجتمع الدولي ،ولاسيما دول الاتحاد الاوربي التي طالما تذرعت بتأجيل قبول تركيـا ضـمن دول الاتحـاد بسياسـتها تجـاه الاكـراد ،وطالما جعلت الاعتراف بالقومية الكردية والاعتراف بحقوقها الثقافيـة والحريـة والديمقراطية شرطا لقبولها (๕๕)

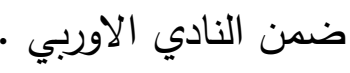

وتعود فكرة الحزب الى مجموعة من شباب الاكراد المثقفين من الذين كانوا يتلقون تعليمهم بكلية العلوم

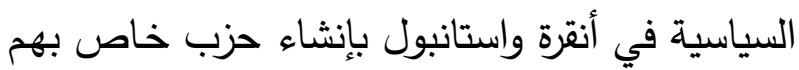
TVT ام ، و وعلى رأسهر عبدالله اوجلان "وكان هؤلاء

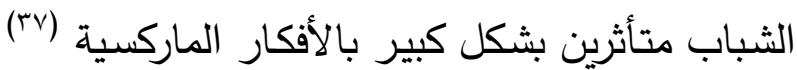
التي اجتاحت الجامعـات والمعاهـد في تلـك الفترة مــؤمنين بـأن حـل القضــية الكرديــة يكـون عبـر

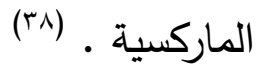
وفي ظل سنوات قليلة تمكن حزب العمال الكردستاني

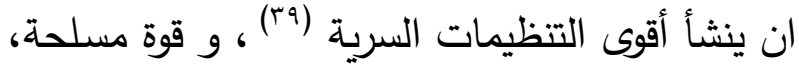

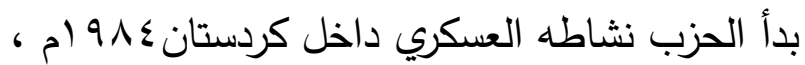

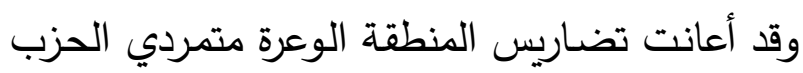
في حربهم ضـــ الجيش التركي. وقـد اتخذوا مـن كردستان العراق منطقة تحمي قواعدهم الخلفية، كما أقـاموا تحالفــاً مــع الــزب الـديمقراطي الكردســاني

اللبناني، الذي يخضع للسبطرة السورية أقام أوجلان معسكر ات التبر التدريب

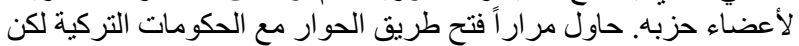

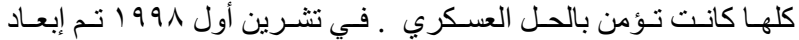

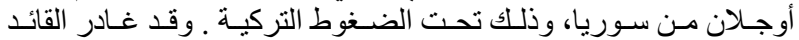

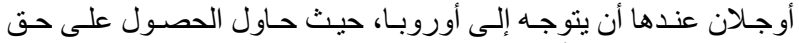

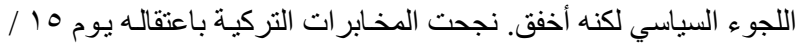

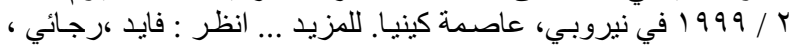

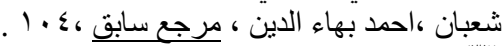

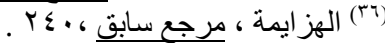

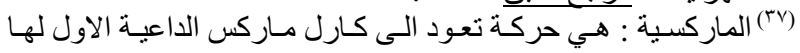

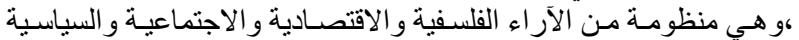

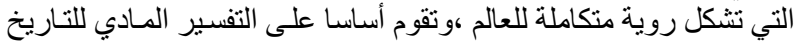

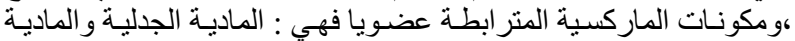

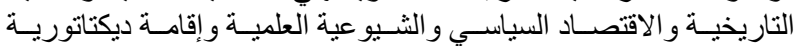

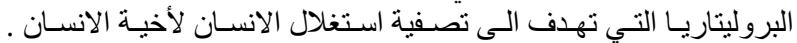

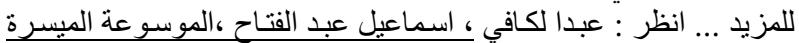

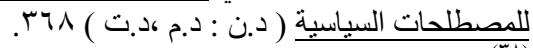
الفئه

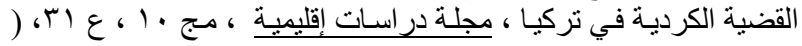

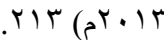
V، غدير ، مرجع سابق (ra) 
قائمة المصادر والمراجع

اولا : الرسائل العلمية

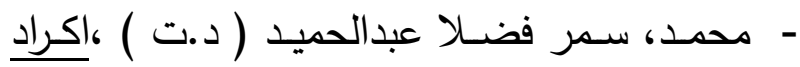

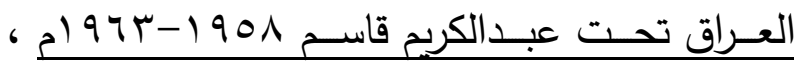

رسالة ماجستير ،جامعة الزقازيق، مصر •

ثانيا : المراجع

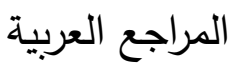

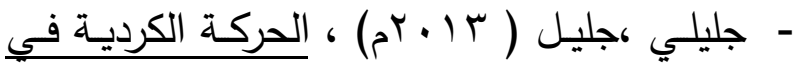

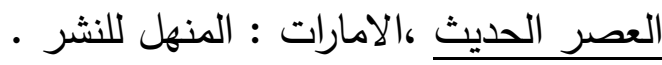

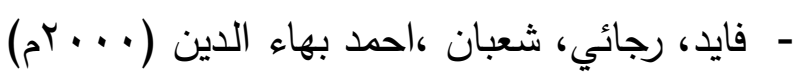

، اوجلان الزعيم ..القضية ، القاهرة : ميريت للنشر

والمعلومات.

- قبيسي ،محمد بهجت ( د.ت) ، الاكرراد والنبـي

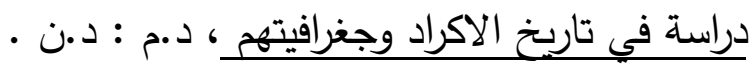

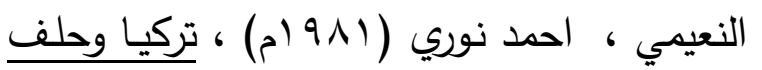

شمالي الأطلسي، عمان: المطبعة الوطنية،

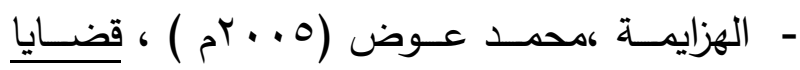

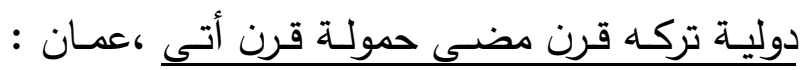
جامعة العلوم التطبيقية.

\section{المراجع المترجمة الى العربية}

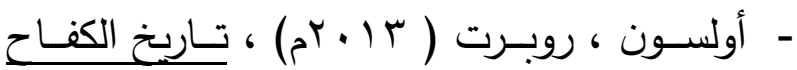

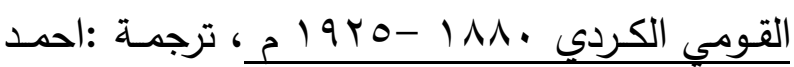

خليل الامارات : المنهل للنشر • - غورغاس، جوردي ، الحركة الكردية التركيـة في

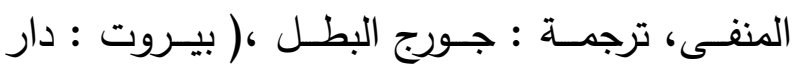

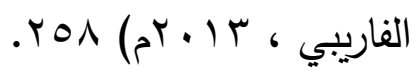

اسـتأنف المسـلحين الأكـراد الهجـوم علـى الجـيش التركـي فـي عـام ء . . rام ،وعـاد حـزب العمــال الكردستاني بقوة مـع نهايـة V .. rم ليجدد عملياتـه

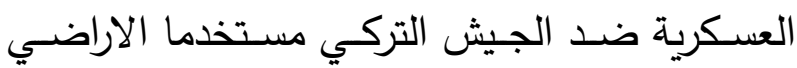
العراقيـة الثمالية وخصوصـا المناطق الجبلية الوعرة فـي إقلـيم كردسـتان قاعـدة لـهـ ـ بالمقابـل قـررت الحكومـة الكردية في العراق القيام بعمليات عسكرية للقضاء على الحزب وهو ما أقره البرلمان ثم عبدالله

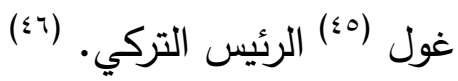
الخاتمة

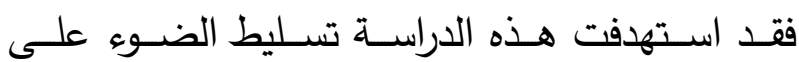

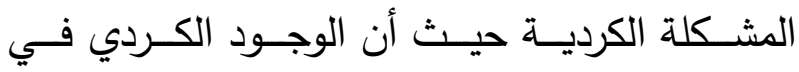

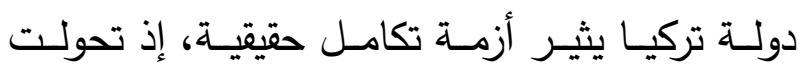

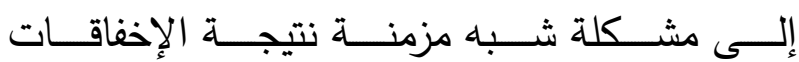

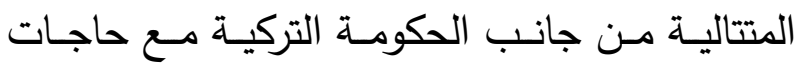
ومتطلبات الثعب الكردي حضارياً وسياسياً.

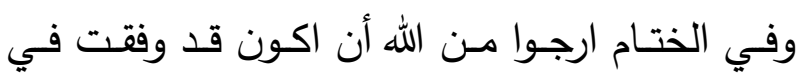

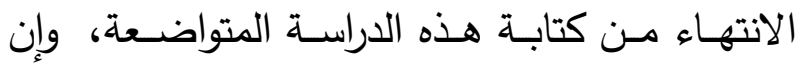

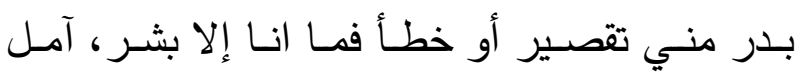

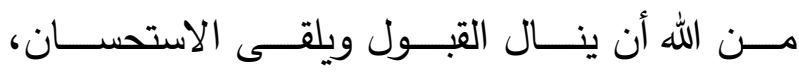

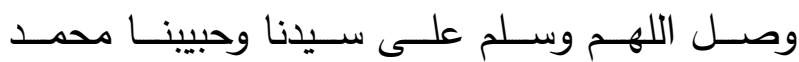
وعلى آله وصحبه أجمعين.

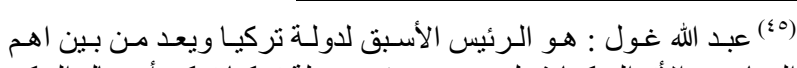

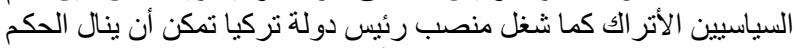

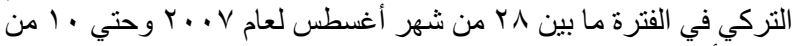

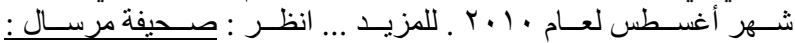

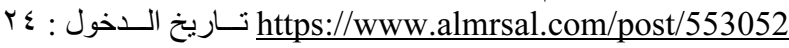


- نور الدين، محمد ، (ع99 (م) ، المسألة الكردية في تركيـا تقـويم للمعطيـات و الاحتمـالات ،مجلـة

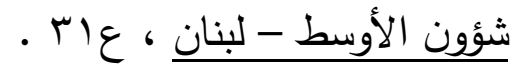

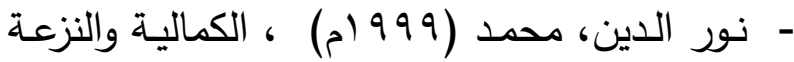
الكرديـة في تركيا ، مجلة شؤون الأوسط - لبنـان . . 9 . $\wedge v_{\varepsilon}$

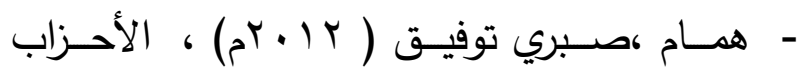

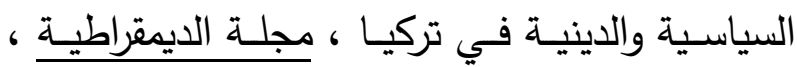
. $r \leqslant \varepsilon$ خامسا : المواقع الإككترونية - صحيفة مرسال : https://www.almrsal.com/post/553052 -

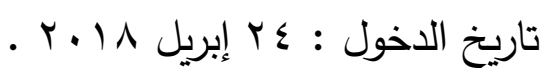
موسوعة مقاتل الصحراء :

Y : https://goo.gl/g5kYq9

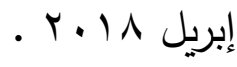
- - مدونة مثل هذا اليوم : -

http://www.zaytoday.com/event/details/50b34

r. تاريخ الدخول : rde3e3c5 - موقح :bbc -

http://www.bbc.com/arabic/middleeast-

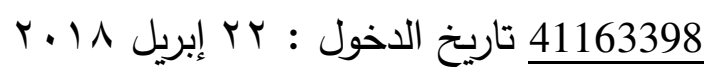
الملاحــق الـولق

أولا : الصور - ملحق رقم (1) صورة اول رئيس لجمهورية تركيا "مصطفى كمال أتاتورك"
ثالثا : الموسوعات - عبـدا لكـافي ؛ـاســماعيل عبــد الفتــاح_(د.ت) ،الموسـوعة الميسـرة للمصـطلحات السياسـية د.ن : - د. - السرجاني، راغب، الموسوعة الميسرة في التاربخ

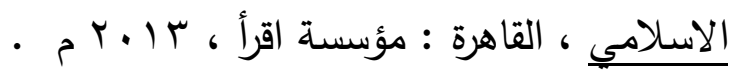
رابعا : الدوريات الجرائد

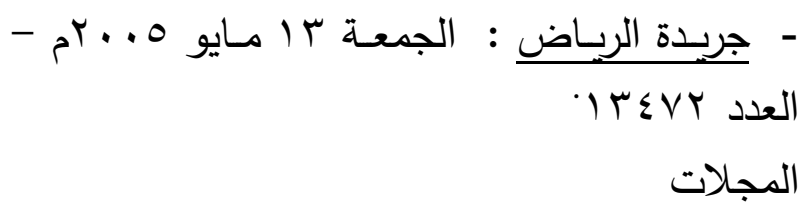

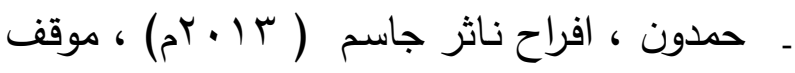
الاحزاب الإسـلامية التركية من القضية الكرديـة في

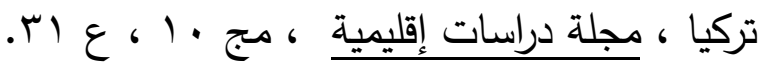

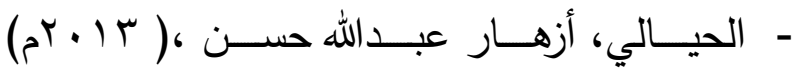

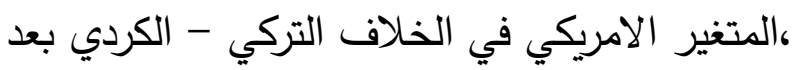
عام ץ . . ب تركيا وحزب العمال الكردستاني ، مجلة

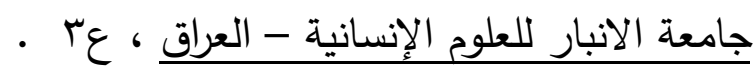

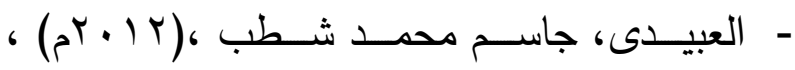
انتفاضــة الكـرد في إقليم درسـيم في جنـوب شـرق

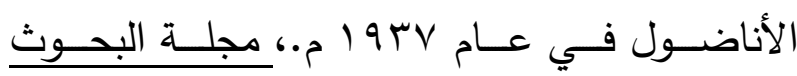

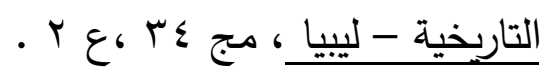

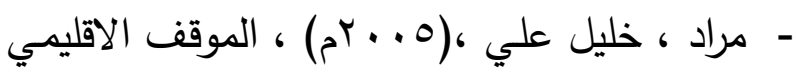

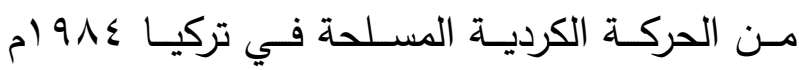

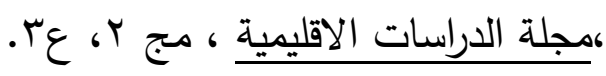
- المعوش، لطفى (999 (م) ، المسألة القومية في الميات

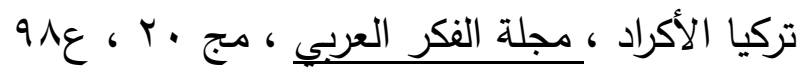




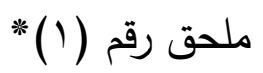

صورة اول رئيس لجمهورية تركيا" مصطفى كمال أتاتورك"

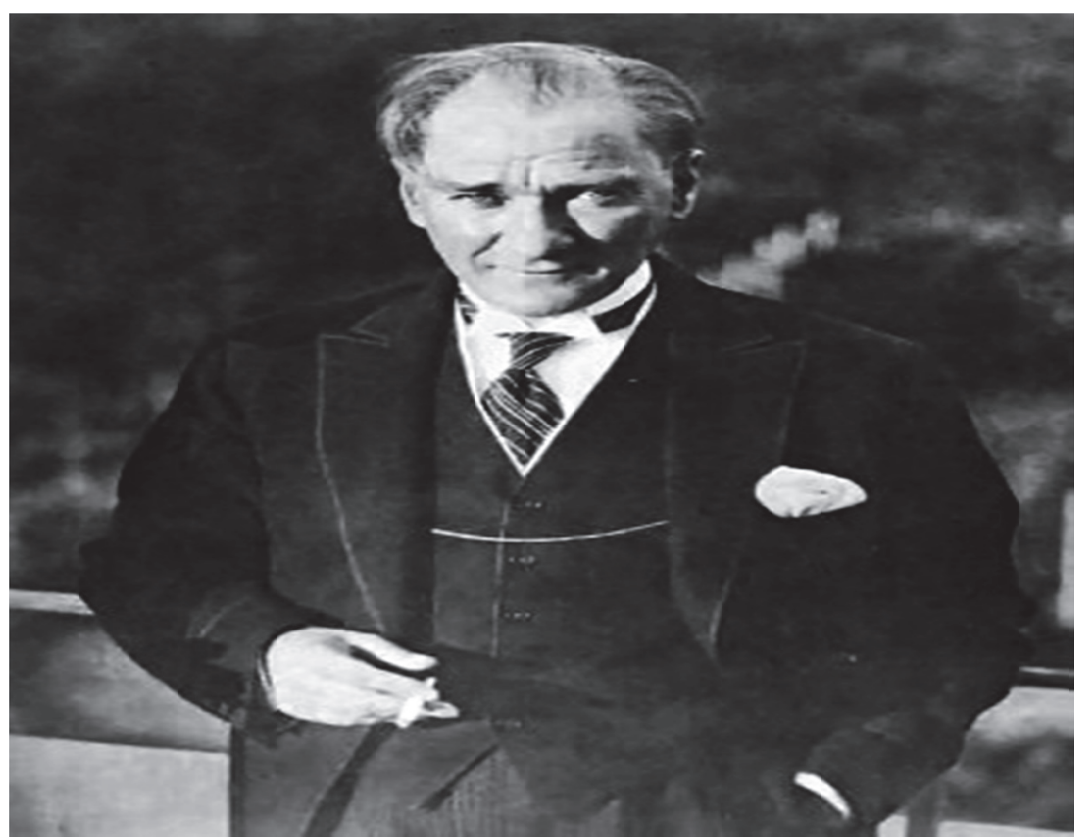

vو (*) موسو عة المعرفة :http://cutt.us/EGDbD تاريخ الدخول 2018 / 4 / 27م. 


$$
\text { أحلام علي الزهراني }
$$

\title{
Almushkilat Alkardiat fi Zili Aljumhuriat Alturkia
}

\author{
Ahlam Aly Al-zahrani \\ Faculty of Arts and Humanities \\ Jeddah - Kingdom of Saudi Arabia
}

Abstract. relations Kurdish in the Republic of Turkey, starting of action alkmale and to the connected events while insisting Kurdish establishment of a Kurdistan State . 